\title{
Circadian rhythms in plasma concentration of 11-hydroxycorticosteroids in men working on night shift and in permanent night workers
}

\author{
R. T. W. L. CONROY', ANN L. ELLIOTT, and J. N. MILLS \\ Department of Physiology, University of Manchester, M13 9PL
}

\begin{abstract}
Conroy, R. T. W. L., Elliott, Ann L., and Mills, J. N. (1970). Brit. J. industr. Med., 27, 170-174. Circadian rhythms in plasma concentration of 11-hydroxycorticosteroids in men working on night shift and in permanent night workers. Blood samples have been collected for estimation of plasma 11-hydroxycorticosteroids from three groups of workers - day and night shift workers in a light engineering factory, and night workers in a newspaper printing works. Up to five samples were collected over $24 \mathrm{hr}$, or two samples per $24 \mathrm{hr}$ were collected for three days. In conformity with the observations of others, day workers showed maximal concentrations in the morning around the time when they started work. In the newspaper workers maximal concentrations were found when they awoke around $14.00 \mathrm{hr}$. Night shift workers in the engineering works showed a greater variety of pattern, some showing the pattern usual in a day worker, some showing a maximum concentration about midnight and a minimum around $06.00 \mathrm{hr}$ and a large proportion showing no clear circadian rhythm.

In the newspaper workers the rhythm was thus well adapted to their pattern of nocturnal work, whereas relatively few of the night shift workers in the engineering works showed such adaptation. It appears that the adrenal cortical rhythm can be adapted to night work in a community in which this is universal, accepted and lifelong, but that such adjustment is unusual in men on night shift work for limited periods, and whose associates are mainly following a usual nycthemeral existence.
\end{abstract}

The occurrence of a circadian rhythm in plasma corticosteroids was first described by Bliss, Sandberg, Nelson, and Eik-Nes (1953). The complete nycthemeral pattern was observed by Perkoff, Eik-Nes, Nugent, Fred, Nimer, Rush, Samuels, and Tyler (1959), who showed that the plasma steroid concentration rose steeply towards the end of sleep and fell during the waking hours.

There is less agreement over the effect of the altered sleep-wakefulness habits of night workers (Migeon,

${ }^{1}$ Present address: Department of Physiology, Royal College of Surgeons in Ireland, St. Stephen's Green, Dublin 2.
Tyler, Mahoney, Florentin, Castle, Bliss, and Samuels, 1956; Conroy, 1967). Since in different industries very different patterns of night work prevail, we have selected for study workers from one where night work is permanent and universal, and from another where night and day shifts are worked.

\section{Subjects}

The subjects were all men as follows:

Group 1 Twenty-three night workers aged 21 to 59 years were from a light engineering factory where shift rotation was practised. Nearly all were on monthly rotation of shifts. The night shift was from 22.00 to $07.00 \mathrm{hr}$ and the 
general rule was for the men to work four nights a week, although some did extra as overtime.

Group 2 Twenty day workers aged 21 to 53 years worked from 07.30 to $16.30 \mathrm{hr}$ in the same factory.

These groups were further subdivided into groups 1a (11) and $2 a(8)$ who were examined first, and $1 b(15)$ and $2 b$ (12) who were examined 12 months later. Three of the night workers were examined on both occasions but are treated as if they were different subjects.

Group 3 Fourteen workers aged 30 to 55 years had for the past 2 to 40 years worked in a newspaper printing works where continuous night work was practised from roughly 20.00 to $05.00 \mathrm{hr}$. These include the 12 subjects briefly reported by Conroy (1967).

Blood was collected by venepuncture as follows:

$\begin{array}{clllllll}\text { Group 1a } & 22.30 & 04.00 & 06.30 & 24.00 & & \\ 1 \mathrm{~b} & 01.00 & 05.30 & 00.30 & 06.30 & 00.30 & 06.00 \\ 2 \mathrm{a} & 08.30 & 13.30 & 16.00 & 09.00 & & \\ 2 \mathrm{~b} & 09.00 & 15.30 & 09.00 & 16.00 & 09.00 & 16.00 \\ 3 & 20.30 & 03.30 & 06.30 & 14.00 & 20.30 & \end{array}$

In Group 3 the 06.30 and $14.00 \mathrm{hr}$ samples were collected at their homes, which was only possible for 10 of the 14 men. In all groups sampling covered a considerable period and the men were not always immediately available so some samples were collected earlier or later than the time indicated; the error never exceeded an hour except in 10 samples in subjects of group 3 . In addition an occasional subject failed to produce one or more samples.

\section{Analytical Methods}

The blood samples were heparinized and centrifuged immediately, and the plasma was refrigerated until analysis. Plasma free 11-hydroxycorticosteroids were estimated by the method of Mattingly (1962) modified by Spencer-Peet, Daly, and Smith (1965).

Duplicate estimations were routinely performed. The $\mathrm{SE}$ of the mean of a random series of 30 such duplicates was $0.2 \mu \mathrm{g} / 100 \mathrm{ml}$. On the rare occasions when this error exceeded $5 \%$ of the mean a third estimation was performed.

\section{Results}

Fourteen of the day workers showed an entirely conventional pattern in their plasma steroids (Fig. 1A): in group 2a this implies that the concentration was highest in the 08.30 or $09.00 \mathrm{hr}$ sample, in group $2 \mathrm{~b}$ that the concentration was always higher at $09.00 \mathrm{hr}$ than at 15.30 or $16.00 \mathrm{hr}$. Two more subjects were nearly normal in that their mean morning exceeded their mean afternoon concentration, whilst the remaining four showed no consistent pattern.

The six subjects in group 3 who contributed the full series of five blood samples showed a consistent pattern with maximum steroid concentration around $14.00 \mathrm{hr}$ when they were rising from sleep and minimal values in the early morning (Fig. 1B). Six

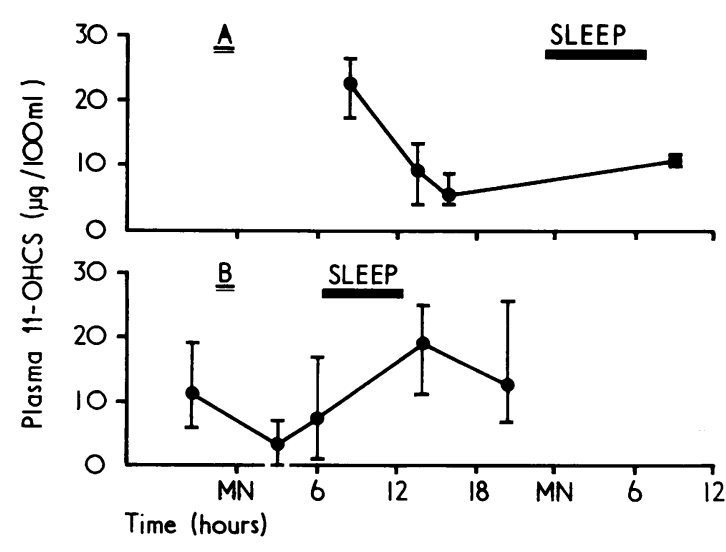

FIG. 1. Plasma 11-hydroxycorticosteroid concentrations: A, four day workers; B, six permanent night workers. Means and ranges.

of the remaining subjects showed an essentially similar pattern in so far as the absence of some values made comparison possible. The results from the remaining two subjects were disregarded since steroid concentration at $20.30 \mathrm{hr}$ on the second occasion was so far above the value $24 \mathrm{hr}$ previously that no rhythmic pattern could be defined.

The night shift workers in group 1 were much less consistent in their behaviour, and in 10 of them no circadian rhythm could be discerned in the plasma steroid concentration. In two from group 1a the concentration rose continuously from the initial midnight sample to the final sample $24 \mathrm{hr}$ later. In eight subjects from group $1 \mathrm{~b}$, observed over three successive nights, the concentration sometimes rose between midnight and $06.00 \mathrm{hr}$ and sometimes fell.

In the remaining 16 subjects a rhythm could be defined since, in those of group 1a, the steroid concentration in the final sample was approximately the same as $24 \mathrm{hr}$ earlier, and in those of group $1 \mathrm{~b}$ the change from midnight to $06.00 \mathrm{hr}$ was fairly consistent. In these 16 subjects the pattern of steroid concentration fell into three clearly-defined groups: six shared the pattern characteristic of day workers, with a midnight minimum and a maximum around $06.00 \mathrm{hr}$, six appeared well adapted to their night hours of work, with a maximum concentration about midnight and a minimum around $06.00 \mathrm{hr}$, and the remaining four subjects, in group 1a, showed a distinctive pattern of their own with maximum at $04.00 \mathrm{hr}$ and minimum at $06.30 \mathrm{hr}$, corresponding to neither the behaviour expected of a day nor that of a night worker (Fig. 2c). Examples of all these patterns are shown in Figure 2. Of the three men who contribute twice to these totals, one was not rhythmic on either occasion and the other two were rhythmic on the first but not on the second occasion. 

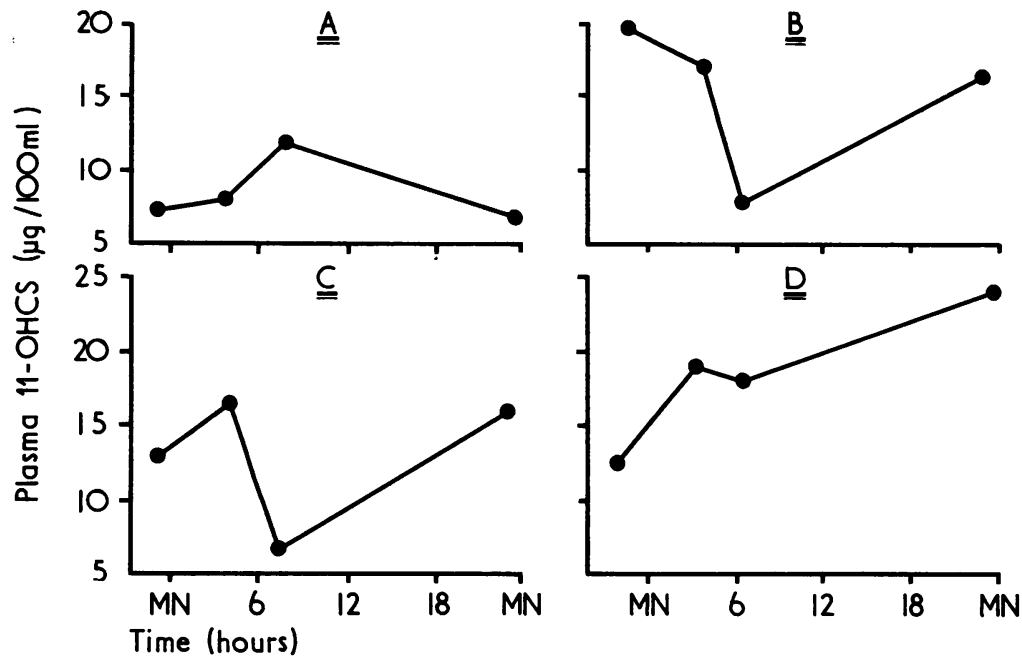

FIG. 2. Plasma 11-hydroxycorticosteroid concentrations in four individual night shift workers in engineering works: $\mathbf{A}$, unadapted pattern as in day workers; B, well adapted to night work; C, partial time-shift, appropriate neither for day nor for night work; $D$, no circadian rhythm evident.

\section{Discussion}

There are very few reports in the literature of the circadian behaviour of plasma hydroxycorticosteroids in night workers. Migeon and his colleagues (1956) studied the rhythm in 10 subjects - nurses and night watchmen who had been on night duty for at least six months - and observed a pattern remarkably similar to that of subjects on day work with the usual fall beginning at around 08.CO hr.

By contrast, Perkoff et al. (1959) claim that the rhythm of plasma 17-hydroxycorticosteroids could be reversed within 5 to 10 days in subjects reversing their sleep habits. Their observations were made on four medical students and four nurses on night duty who were provided with a quiet dark room in which they were expected to sleep from 08.00 to $15.00 \mathrm{hr}$.

This appears to be not a reversal but an eight-hour shift in their sleep habits, and the phase of the plasma steroid rhythm had also shifted by eight hours and attained a maximal concentration in the $16.00 \mathrm{hr}$ sample. The amplitude of the rhythm was very low compared with that usually observed in day workers. No indication of individual variation is given but it is stated that the time shift consisted of first a fall in the concentration in the $08.00 \mathrm{hr}$ sample followed by a rise in the concentration observed at $16.00 \mathrm{hr}$. The difference between these results and those of Migeon and his colleagues(1956) on subjects who had been on night work for a much longer period may be ascribable to the very good conditions provided for them to sleep and to the regular existence to which they were required to adhere.

Preliminary observations in this department on urinary steroids (Imrie, unpublished) suggested that, in a factory where day and night shifts are worked, some night workers had adapted and some nonadapted steroid rhythms. Kojima and Niiyama (1965) have also reported a disturbance, without full adaptation, in the rhythm of excretion of 17ketogenic steroids by night workers. This impression was confirmed by Conroy (1967) who collected plasma samples at the start and at the end of the night shift from workers in the same two establishments where we have now made more extensive studies. In the present investigation the plasma corticosteroid rhythms for most of the day workers conform with the pattern which has been generally recorded (Perkoff et al., 1959; see Mills, 1966 for further references) and which has been regularly observed in this laboratory. The occurrence of some irregular results is not surprising since many factors other than the circadian influence, including the stress of venepuncture, are known to affect plasma steroid concentration. Furthermore, blood samples collected four times in $24 \mathrm{hr}$ are inadequate to define the full course of plasma steroid concentrations, since there is a series of elevations and depressions towards the end of the usual sleep period (Weitzman, Schaumburg, and Fishbein, 1966; Weitzman, Goldmacher, Kripke, MacGregor, Kream, and 
Hellman, 1968). Sampling at this time of day could give erratic values which did not regularly recur each day, and in subjects not following nycthemeral habits, we may have sampled during such a phase.

The difference between the behaviour of the two groups of night workers is, however, striking. The whole social life of the newspaper workers centres around an acceptance of permanent night work for themselves and their regular associates, and their steroid rhythms are well adapted to such habits. Figure 3 shows the results of an earlier investigation briefly reported by Conroy (1967) in which blood samples were collected only at the start and finish of work, and which illustrates the degree of consistency between subjects. By contrast, the engineering workers are mostly on night shift for only a limited period, which interferes with their social life. Most of them dislike night work apart from its financial reward. Few have their steroid rhythms well adapted and some adhere to the usual pattern of diurnal workers, and a larger proportion than in either of the other groups fail to show a regular rhythm. This may well result, like similar irregularities in other rhythms, from a conflict between the influences of their pattern of work and of the supposed internal circadian mechanisms, reinforced by their returning to a diurnal existence at week-ends.

It is unfortunate that we were unable to collect

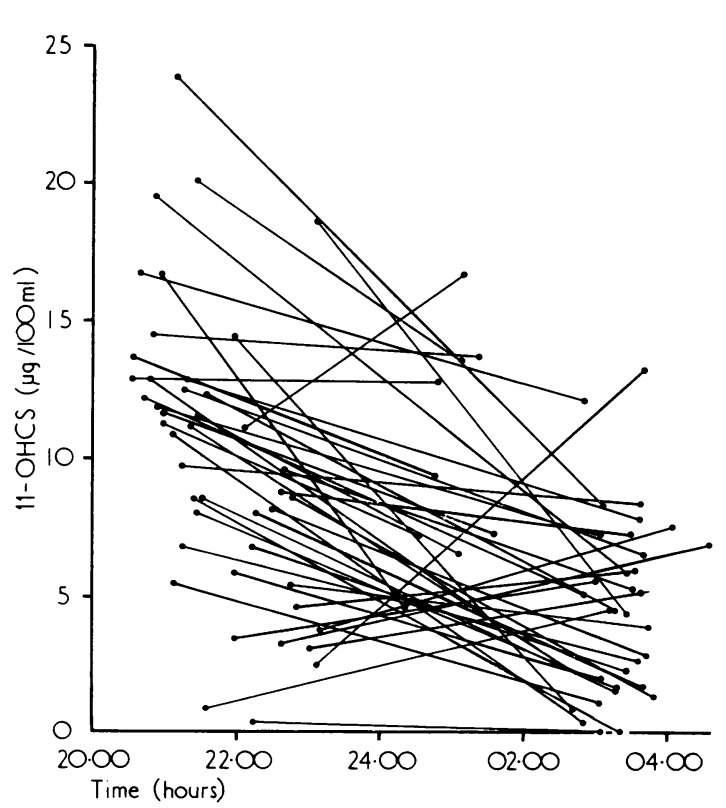

FIG. 3. Plasma 11-hydroxycorticosteroid concentrations in workers at newspaper printing works around time of starting and finishing work. blood from every subject at precisely the same time. However, the scatter in sampling times was greater in the newspaper workers than in the other groups, and as it is these who showed the most consistent temporal pattern in plasma steroid concentration, the irregularity in the sampling times cannot have biased our results.

It is worth remarking here that the pattern of life of night workers seldom represents a simple time-shift from the pattern of day workers, and it is not therefore comparable with the time-shift experienced by travellers. Most people follow a sequence work-recreation-sleep whilst most of the night workers follow the sequence work-sleeprecreation. The expected pattern of steroid concentration depends upon whether the usual early morning rise in secretion is regarded as a preparation for work as opposed to leisure, or for wakefulness as opposed to sleep. The rhythm of the newspaper workers suggests the latter since their highest concentrations were observed when they were rising from sleep before their leisure activities.

The behaviour of those engineering workers whose maximum was at $04.00 \mathrm{hr}$ and minimum at $06.30 \mathrm{hr}$ admits of no such explanation. It resembles rather the usual circadian rhythm which has been partially shifted backwards in time. Similar partial time-shifts in circadian rhythms have been observed in other circumstances. Völker (1926) found a partial timeshift of the rhythms of pulse-rate and temperature after an artificial time-shift in the laboratory: and we have made a similar observation on a number of rhythms during the course of adaptation to a new time zone after eastward and westward flights (Elliott and Mills, 1969; Conroy and Hall, 1969; Fort, 1969, and unpublished observations).

A greater variety of patterns and more irregularities were observed in the night shift workers at the engineering works than in either of the other groups; this may represent differences between one man and another, such as could result from different home or other circumstances, or from an inherently different adaptability. However, since we were unable to examine the same subjects repeatedly, we do not know whether some men would follow consistently one or other of the patterns. Thus we cannot as yet assess a man's suitability for night work solely on the basis of the adaptation of his circadian rhythms in plasma steroids. It may well be that the adrenal rhythms as well as the body temperature rhythm (Teleky, 1943; Chadwick-Jones, 1967) should be considered in any assessment of the physiological basis for night and shift working.

The varying responses of different men to the same conditions of work have also permitted us to compare the adaptation of adrenal and urinary rhythms. This will be considered in a subsequent paper (Conroy, Elliott, and Mills, in preparation). 
The authors wish to acknowledge the co-operation of the workers who so readily volunteered to give blood samples, and of the managements and medical staffs of the engineering and newspaper printing works. Our thanks are due also to Miss M. Hall for her skilled technical assistance.

\section{References}

Bliss, E. L., Sandberg, A. A., Nelson, D. H., and Eik-Nes, K. (1953) The normal levels of 17 -hydroxycorticosteroids in the peripheral blood of man. J. clin. Invest., 32, 818-823.

Chadwick-Jones, J. (1967). Shift working: Physiological effects and social behaviour. Brit J. industr. Relations, 5, 237-243.

Conroy, R. T. W. L. (1967). Circadian rhythms of plasma 11-hydroxycorticosteroids in night-workers. J. Physiol., 191, 21-22P.

- and Hall, M. D. (1969). Adrenal cortical function and body temperature rhythms after a transatlantic flight. J. Physiol., 200, $123 P$.

Elliott, A. L., and Mills, J. N. (1969). Urinary potassium rhythms before and after transatlantic flight. J. Physiol., 200, 122P.

Fort, A. (1969). The effects of rapid change in time zone on circadian variation in psychological functions. J. Physiol., 200, 124P.

Kojima, A., and Niiyama, Y. (1965). Diurnal variations of 17ketogenic steroid and catecholamine excretion in adolescent and middle-aged shift workers with special reference to adaptability to night work. Industrial Health, 3, 9-19.

Mattingly, D. (1962). A simple fluorimetric method for the estimation of free 11-hydroxycorticoids in human plasma. J. clin. Path., 15, 374-379.
Migeon, C. J., Tyler, F. H., Mahoney, J. P., Florentin, A. A., Castle, H., Bliss, E. L., and Samuels, L. T. (1956). The diurnal variation of plasma levels and urinary excretion of 17-hydroxycorticosteroids in normal subjects, night workers and blind subjects. J. clin. Endocrinol., 16, 622-633.

Mills, J. N. (1966). Human circadian rhythms. Physiol. Rev., 46, 128-171.

Perkoff, G. T., Eik-Nes, K., Nugent, C. A., Fred, H. L., Nimer, R. A., Rush, L., Samuels, L. T., and Tyler, F. H. (1959). Studies of the diurnal variation of plasma 17-hydroxycorticosteroids in man. J. clin. Endocrinol., 19, 432-443.

Spencer-Peet, J., Daly, J. R., and Smith, V. (1965). A simple method for improving the specificity of the fluorimetric determination of adrenal corticosteroids in human plasma. J. Endocrinol., 31, 235244.

Teleky, L. (1943). Problems of nightwork: influences on health and efficiency. Industr. Med., 12, 758-779.

Völker, H. (1926). Úber die tagesperiodischen Schwankungen einiger Lebensvorgänge des Menschen. Pflügers Arch. ges. Physiol., 215, 43-77.

Weitzman, E. D., Goldmacher, D., Kripke, D., MacGregor, P., Kream, J., and Hellman, L. (1968). Reversal of sleep-waking cycle: effect on sleep stage pattern and certain neuroendocrine rhythms. Trans. Amer. neurol. Ass., 93, 153-157.

-, Shaumburg, H., and Fishbein, W. (1966). Plasma 17-hydroxycorticosteroid levels during sleep in man. J. clin Endocrinol., 26, 121-127.

Received for publication September 8, 1969.

\section{The January (1970) Issue}

The subacute inhalation toxicity of 109 industrial chemicals J. C. GAGE

Vibration syndrome A. M. STEwart AND D. F. GodA

Interrelationships between lead in blood, lead in urine and ALA in urine during lead work STIG SELANDER AND KIM CRAMÉR

Determination of lead chelated with ethylenediaminetetra-acetic acid in blood after precipitation of protein with perchloric acid A. A. CERNIK

Urinary excretion of hippuric acid and $m$ - or $p$-methylhippuric acid in the urine of persons exposed to vapours of toluene and $m$ - or $p$-xylene as a test of exposure M. OGATA, K. TOMOKUNI, AND Y. TAKATSUKA

The toxicity of diquat D. G. Clark AND E. W. Hurst

Arsine poisoning A. G. Hocken AND G. BradshaW

Sickness absence and ventilatory capacity of workers exposed to sulphuric acid mist M. K. WILLIAMS

Ampicillin in the treatment of brucellosis D. G. McDevitt

Effect of microwaves at $\mathrm{X}$-band on guinea-pig skin in tissue culture.

3. Effect of pulsed microwaves on skin respiration and biochemistry S. A. CARNEY, J. C. LAWRENCE, AND

C. R. RICKETTS

\section{Obituary}

Notes and miscellanea

Medical aspects of trawler safety F. P. ElLIS

Who started it all? BRIAN HARVEY

Erythrocytes of uranium miners: the red blood picture $Z$. VİCH AND J. KR̆IKLAVA

Book reviews

\section{Current awareness}

A number of copies are are still available and may be obtained from the Publishing Manager, British Medical Association, Tavistock Square, London W.C.1, price 22s. $6 d$. 